\title{
TWO ARGUMENTS SUPPORTING THE THESIS OF THE PREDICTIVE NATURE OF REASONS FOR ACTION
}

\begin{abstract}
The dominant view in contemporary philosophy of action is that, to explain an action we need to provide a reason for it. A reason is what rationalises an action. According to Donald Davidson, before we can describe a reason we must identify the need that accompanies the performance of a given action, as well as the specific attitude of the agent to the action. The author of Action, Reason and Cause believes that the proattitude/belief pair helps determine the reason for action, which is at the same time the action's cause. Davidson's view has a lot of supporters today and is strictly related to the so-called post-Humean theories of action. The objective of the present analysis is to demonstrate that the primary reason for action is not provided by the pro-attitude/belief pair, but by predictions due to which agents act in such and such a way. This expands on Elizabeth Anscombe's intuition according to which each intention is predictive in nature. I will support the thesis about the predictive nature of reasons for action by means of two arguments. The first argument relies on the analysis of the Knobe effect concerning the asymmetry between attributing intentionality and attributing responsibility for actions; the other draws upon the theory of predictive processing.

The remainder of this paper has the following structure: in $\S 1$, I will discuss Donald Davidson's theory. §2 will focus on Elizabeth Anscombe's conception. In §3, I will examine an argument drawn from the analysis of the Knobe effect, according to which an agent will intentionally perform a given action when he can predict the effects of performing it. $\$ 4$ will introduce the problem of providing reasons for action in the context of folkpsychological explanations. \$5 will examine the theory of predictive processing. $§ 6$ will demonstrate that predictions serve a specific, normative role in the decision-making processes, whereas $\S 7$ will advance the argument from predictive processing whereby to explain an action is to identify specific predictive reasoning which caused the action to be performed. In the Conclusions, I will show the consequences of my main thesis for the problem of the nature of actions and explanations, as well as the rationale for using folk-psychological categories.
\end{abstract}

Keywords: reason for action, agency, normativity, Knobe effect, predictions, predictive processing, folk psychology, uncertainty

1. Introduction. 2. The conception of reasons for action in Donald Davidson's approach. 3. Elizabeth Anscombe's conception of intention for action. 4. The problem of reasons for actions and 
the Knobe effect: a first argument. 5. Reasons for action and folk psychology. 6. Action-oriented predictive processing. 7. Decision-making from the perspective of predictive processing.

8. The case from predictive processing: a second argument. 9. Conclusion.

\section{INTRODUCTION}

The aim of the present analysis is to demonstrate that reasons for action are predictions due to which the agent takes such and such action. This expands on Elizabeth Anscombe's intuitions according to which each intention is predictive in nature. I will support the thesis of the predictive nature of reasons for action with two arguments. The first argument relies on the analysis of the Knobe effect concerning the asymmetry between attributing intentionality and attributing responsibility for actions; the other draws on the theory of predictive processing.

The remainde of this paper has the following structure: in $\$ 2$ I will discuss Donald Davidson's theory. In \$3 I will focus on Elizabeth Anscombe's conception. In the next section I will examine an argument drawn from the analysis of the Knobe effect. I will conclude that the agent will perform a given action intentionally when he can predict the consequences of performing it. In \$5 I will discuss the problem of providing reasons in the context of folk-psychological explanations. §6 will examine the theory of predictive processing. In $\$ 7$ I will demonstrate that predictions serve a specific, normative role in the decision-making processes, whereas $\$ 8$ will advance the argument from predictive processing whereby to explain an action is to identify the specific instance of predictive reasoning which caused the action to be perfomed. In the Conclusions, I will show the consequences of my main thesis for the problem of the nature of actions and explanations, as well as the rationale for using folkpsychological categories. 


\section{THE CONCEPTION OF REASONS FOR ACTION IN DONALD DAVIDSON'S APPROACH}

In Actions, Reasons and Causes Davidson begin his analysis by discussing the question of the nature of the relation between the reason for action and the action itself. This question is important because it is the reason that is supposed to explain a given action. In a way, therefore, reasons rationalise actions. According to Davidson, rationalisation consists in a variety of causal explanations. If someone did something because of some reasons, he may be described as: a) having some sort of pro-attitude or grounds to act in such and such a manner; and b) believing (knowing, noticing, remembering, etc.). Davidson understands pro-attitudes as desires, urges, promptings, moral views, aesthetic principles, economic prejudices, social conventions, public and private goals, etc. ${ }^{1}$

Thus, to provide a reason for an action performed by the agent is to single out a certain pro-attitude ${ }^{2}$ and belief shared by the agent. Davidson called the pro-attitude/belief pair the primary reason. Primary reasons explain why the agent performed an action. Providing such a reason is essential and sufficient to understand how a reason of any kind rationalises an action. Davidson claims that it should therefore be treated as a cause for a given action. Let us consider a simple example: when I press the light switch, I turn on the light and the room becomes illuminated. I pressed the switch because I wanted to turn on the light. By saying that I wanted to turn on the light, I explain (give reason, that is rationalise) why I pressed the switch. By giving such a reason, however, I do not rationalise

1 D. Davidson, Actions, Reasons and Causes, The Journal of Philosophy 60(1963)23, 685-686.

2 Ralf Stoecker highlights the fact that Davidson's concept of an attitude is replaced by philosophers with the concepts of "wanting" or "desire". R. Stoecker, Davidson, in: A Companion to the Philosophy of Action, ed. T. O'Connor, C. Sandis, Blackwell, Oxford 2010, 598. 
the act of turning on the light or illuminating the room. Reasons may rationalise an action by setting out the necessary requirements for its primary reason. Generalising from this example, Davidson claims: " $R$ is a primary reason why an agent performed the action $A$ under the description $d$ only if $R$ consists of a pro attitude of the agent toward actions with a certain property, and a belief of the agent that $A$, under the description $d$, has that property". ${ }^{3}$

We may now ask how my wanting to turn on the light becomes part of the primary reason. According to Davidson, there is a verbal parallelism between the statements "I turned on the light" and "I wanted to turn on the light". The first refers directly to an event; we can conclude that the second concerns the same event. It is obvious, of course, that the event of my turning on the light is not related to these sentences in the same way as the existence of the event is related to the truth of "I turned on the light", but not to the truth of "I wanted to turn on the light". If the reference were the same in both sentences, the second sentence would contain the first. However, that is not the case. The sentences are logically independent. Davidson says that wants and desires are shaped by physical objects. The sentence "I want that gold watch in the window" does not identify a primary reason and does not explain why I went into the shop. It only suggests a primary reason contained in the sentence "I wanted to buy a watch".

Since the sentences "I turned on the light" and "I wanted to turn on the light" are logically independent, the first can be used to identify a primary reason only to the extent that the second sentence is true. The reason gives minimal information. It implies that the action is intentional, and that wanting requires some attitude such as a sense of duty or obligation. This is closely related to the action itself and the context of explanation.

3 D. Davidson, Actions, Reasons and Causes, op. cit., 687. 
To know a primary reason is to know an intention with which the action was performed. To know the intention, however, it is not necessary to know the primary reason. If John went to church with the intention of pleasing his mother, then he must have an attitude towards pleasing his mother. However, we need more information to be able to tell whether his reason is that he enjoys pleasing his mother, or thinks it his duty or obligation. Even though the expression "the intention with which John went to church" has the outward appearance of a description, it is in fact syncategorematic ${ }^{4}$ and cannot therefore be taken to refer to some objects, states, dispositions or events. In this context, the expression generates new descriptions of actions in terms of their reasons. The sentence "John went to church with the intention of pleasing his mother" is a new, fuller description of the action previously described as "John went to church".

Davidson claims that when we ask an agent why he acted as he did, we want to obtain an interpretation. His behaviour may seem strange, alien and incomprehensible; or perhaps we cannot recognise an action in it. When we learn his reason, we have an interpretation, a new description of what he did that fits into a familiar picture. Such a picture includes beliefs and attitudes of the agent, but it can also refer to his goals, principles, etc. It does not identify the agent's intention, however, as a given rationalised action may be triggered by many different causes. We can never be sure which particular cause overlaps with the intention of the agent. ${ }^{6}$

In conclusion, Davidson's conception is focused on the analysis of reasons understood as causes of a given event. To identify a reason

4 Syncategorematic terms do not have an independent meaning. Their role is limited to serving a specific syntactic function. They are logical links and modifiers such as each; and; or. Categorematic terms have full semantic meaning. Depending on the context, they may occur as names or functors. Examples of categorematic terms include Paul, $S, P$, blue.

5 D. Davidson, Actions, Reasons and Causes, op. cit., 690.

6 D. Davidson, Freedom to Act, in: D. Davidson, Essays on Actions and Events, Clarendon Press, Oxford 2001, 79. 
is to rationalise an action, that is provide its cause expressed in terms of the agent's attitudes and beliefs.

\section{ELIZABETH ANSCOMBE'S CONCEPTION OF INTENTION FOR ACTION}

Anscombe begins her discussion by saying that, when analysing the concept of an intention we must distinguish between three basic ways of its linguistic expression. These are:

1. expression of an intention, e.g. I intend to open the window;

2. action as intentional, e.g. I am opening the window;

3. intention with which actions are perfomed, e.g. I am opening the window to cool down the room. ${ }^{7}$

Right at the beginning, the author of Intention underlines that, despite these semantic differences, there is only one sense of the concept of an intention. Its spectrum, however, is very wide: from the pure intention of doing something to acting in line with a certain intention to intentional action. The expression of an intention is a prediction of practical rather than theoretical nature. Intention as prediction refers to the future, that is to states of affairs that have not happened yet. As a result, Anscombe concludes that intentions do not refer to any mental states.

If intentions do not refer to states of the agent, how can intentional actions (if they exist at all) be differentiated from events that are not intentional? Anscombe has a ready answer to this question. She believes that actions can be addressed with a special sense of the "why?" question, according to which the answer to this question contains the reason for a given action. ${ }^{8}$ This question does not concern situations where someone says, for example, "I was not aware I did this". The knowledge necessary to answer the "why?" question is not based on evidence, testimony or observations. It

7 G.E. M. Anscombe, Intention, Harvard University Press, Cambridge MA 1957, 1.

8 Ibidem, 9. 
must be non-observational. The subject's surprise at what he did would provide the most convincing evidence that a given action was not performed intentionally. Knowledge of our actions is similar to knowledge about the position of our limbs. The latter is not based on any acts of will, behaviours, etc. ${ }^{9}$

Mental states are strictly related to motives which we cannot know through observational knowledge, just like in the case of intentions. According to Anscombe, motives determine directly a series of actions as their driving force. This is why there is a tendency to consider motives or believes a type of mental causes. This approach, however, is wrong. To borrow a phrase from the late Wittgenstein, we are confused by the external form of declarative statements about motives. ${ }^{10}$

According to Anscombe, it makes sense to differentiate between actions and non-actions only when the answer to the "why?" question indicates a motive: a past event, an interpretation of a given action or an event to happen in the future. There is no sense in answers such as "I was not aware when I was doing it", "I observed what I was doing" or answers based on testimony or indications of a cause, including mental causes. Anscombe's key argument is that we must be able to answer the "why?" question by referring to what was intended rather than intentionally done. The answer to the "why?" question

9 Anscombe underlines that we can also know our "mental states" - feelings, thoughts and moods - without observation. This does not mean, however, that they can be used to explain actions. This remark is important in the context of the discussion of Hume's conception of a cause as something we know without observation. On this, see J. McDowell, Anscombe on Bodily Self-Knowledge, in: Essays on Anscombe's Intention, eds. A. Ford, J. Hornsby, F. Stoutland, Harvard University Press, Cambridge MA 2011, 128-146.

10 Anscombe identifies three types of motives: (1) backward-looking motives - retrospective motives, e.g. revenge, pride, remorse; (2) motives-in-general-general motives that allow us to interpret or describe an action as such and such; and (3) forward-looking motives predicting motives. They are intentions describing future states of affairs. The last class of motives is particularly relevant to my discussion. G.E.M. Anscombe, Intention, op. cit., $18-21$. 
must be reducible to the following - "If I do $p$ with intention $Q$, then $Q$ ". The expression "with intention" indicates an internal, teleological structure of action.

Anscombe gives the famous example of a man who pumps water to replenish a water-supply in a house, moving his arm up and down. ${ }^{11}$ The water is poisoned and the man pumping the water does not know it. He is convinced that he is supplying the people living in the house with clean water. Anscombe is interested in what the man is doing and how his actions can be described. We may ask the man: "Why are you performing action X?". In this specific case, the question would be: "Why are you moving your arm up and down?". The man can answer this question in the following ways: (1) "I'm pumping"; (2) "I'm drawing water from the well"; (3) "I'm supplying water to the household residents". He cannot say, however, (4) "I want to poison the household residents". Anscombe is particularly interested in statement (3) as it focuses not on what the man is doing, but on what he intends to do or achieve. It expresses a future-oriented intention, an intention to act, rather than the intention with which he performs a given action. Anscombe claims that in in the case of the man who pumps water, we have one action which may be described in several ways. Each description depends on different circumstances, and each is a description making the subsequent description possible. Anscombe concludes that human actions are similar in their teleological structure (sometimes simple, sometimes more complex), which consists in the different stages of what the agent is doing. In this example, the action will be intentional under the description "I supply water to the inhabitants of the house", but not under the description "I want to poison the household residents".

11 Ibidem, 37-38. 
The man intentionally supplies water to the residents, unintentionally poisoning them. ${ }^{12}$

In the account advanced by the philosopher, the structure of the intentional action is also the structure that explains the action. The answer to why a person is doing what he is doing refers directly to the internal reason explaining the action. Rather than describing some internal state of his mind, the intention of the person who pumps the water serves the function of the cause-and-effect action. Thus, the reason of a given action is an intention as prediction.

Anscombe's conception relates reasons to the predictive dimension of practical intentions. Intention, however, is not mental or cognitive; rather, it is primarily captured by statements expressing the agent's intentions. Actions are intentional under certain descriptions. It seems that this solution allows Anscombe to avoid reducing the explanation of activities to the language of folk psychology. ${ }^{13} \mathrm{~A}$ close analysis of the example she provides, however, might give one the impression that, to some extent, identifying the intention ultimately depends on the state of the agent's knowledge - the man knew he was pumping water, but did not know that he was poisoning the people living in the house. ${ }^{14}$

\section{THE PROBLEM OF REASONS FOR ACTIONS AND THE KNOBE EFFECT: A FIRST ARGUMENT}

In his article Intentional Action and Side Effects in Ordinary Language, Joshua Knobe brought attention to an asymmetry in attributing

12 In a way, Anscombe anticipates Davidsons' thesis whereby all actions are intentional under a certain description. A given action may be intentional under one description, but not under another.

13 I will address the problem of folk psychology later in this article.

14 It is important to remember that knowledge of intentions is not observational. It is operational knowledge-how, rather than theoretical knowledge-that. This is why we cannot unequivocally put Anscombe into the category of thinkers acknowledging the important explanatory role of folk-psychological concepts. This issue, however, must remain at the margins of the present analysis. 
intentionality to actions depending on their side-effects. ${ }^{15} \mathrm{He}$ is specifically interested in the source of this asymmetry: when accounting for the side-effects of an action, why do people tend to attribute intentionality to the agent's actions in some cases but not in others? It seems that there must be a link between attributing intentionality and attributing responsibility according to side-effects. Such a link is, however, by no means clear. According to Knobe, "an asymmetry whereby people are considerably more willing to blame the agent for bad side-effects than to praise the agent for good side-effects. And this asymmetry in people's assignment of praise and blame may be at the root of the corresponding asymmetry in people's application of the concept intentional: namely, that they seem considerably more willing to say that a side-effect was brought about intentionally when they regard that side-effect as bad than when they regard it as good." ${ }^{16}$

15 In order to prove the existence of this asymmetry, Knobe carried out the following experiment: 78 persons were presented with one of two scenarios: "harm" and "help". J. Knobe, Intentional Action and Side Effects in Ordinary Language, Analysis 63(2003)3, 191.

Harm scenario: "The vice-president of a company went to the chairman of the board and said, 'We are thinking of starting a new program. It will help us increase profits, but it will also harm the environment.' The chairman of the board answered, 'I don't care at all about harming the environment. I just want to make as much profit as I can. Let's start the new program.' They started the new program. Sure enough, the environment was harmed." Help scenario: "The vice-president of a company went to the chairman of the board and said, 'We are thinking of starting a new program. It will help us increase profits, and it will also help the environment.' The chairman of the board answered, 'I don't care at all about helping the environment. I just want to make as much profit as I can. Let's start the new program.' They started the new program. Sure enough, the environment was helped." Most people (82\%) who were presented with the first scenario decided that the CEO provoked a side-effect (harming the environment) intentionally. Most people who were presented with the second scenario (77\%) said that the side-effect (helping the environment) was not provoked by the CEO intentionally. We analysed these experiments in: M. Piekarski, Efekt Knobe'a, normatywność i racje działania, Filozofia Nauki 97(2017)1, 109-128. See also: K. Paprzycka, Rozwiq̨zanie problemu Butlera i wyjaśnienie efektu Knobe'a, Filozofia Nauki 22(2014)2, 73-96.

16 J. Knobe, Intentional Action and Side Effects in Ordinary Language, op. cit., 193. Discussion (inter alia): F. Cushman, A. Mele, Intentional Action: Two-and-Half Folk Concepts? 
The problem raised by Knobe sparked wide debate. ${ }^{17}$ In this article, I am interested in the implications of Knobe's analyses for the problem of identifying reasons for actions. First, studies in experimental philosophy, of which the author of Intentional Action and Side Effects in Ordinary Language is a prominent representative, have shed new light on traditional answers to philosophical problems broached by analytical philosophy of action and mind. Second, such studies undermine the so-called Simple View on the relation between actions and intentions. According to this view, subject $S$ performs action $\varphi$ intentionally only when $S$ intends to do $\varphi$ :

\section{If $S$ is $\varphi$-ing intentionally, then $S$ has the intention of $\varphi$-ing. ${ }^{18}$}

In what follows I will focus on the analysis of the problem raised by Knobe. I will demonstrate that there are actions that do not comply with the requirement imposed by the Simple View. Some researchers suggest replacing the Simple View with a different conception: „View II holds that there are cases where $S$ intentionally does A without intending to do A, as long as doing $\mathrm{A}$ is foreseen and $S$ is willing

in: Experimental Philosophy, eds. J. Knobe, S. Nichols, New York: Oxford University Press 2008, 171-188; J. Knobe, The Concept of Intentional Action: A Case Study in the Uses of Folk Psychology, in: Experimental Philosophy, eds. J. Knobe, S. Nichols, Oxford University Press, New York 2008, 129-148; A. Mele, Intentional action: Controversies, data, and core hypotheses, Philosophical Psychology 2(2003), 325-340; E. Machery, R. Mallon, S. Nichols, S.P. Stich, Semantics, cross-cultural style, Cognition 3(2004), 1-12; T. Nadelhoffer, Blame, Badness, and Intentional Action: A Reply to Knobe and Mendlow, Journal of Theoretical and Philosophical Psychology 24(2004), 259-269; S. Nichols, J. Ulatowski, Intuitions and Individual Differences: The Knobe Effect Revisited, Mind and Language 4(2007), 346-365.

17 I don't have space in this article to discuss this issue.

18 See: F. Adams, Intention and Intentional Action. The Simple View, Mind and Language 4(1986)1, 281-301; H. McCann, Rationality and the Range of Intention, Midwest Studies in Philosophy 10(1986)1, 191-211. 
to accept A as a consequence of $S$ 's action". So $S$ did A intentionally, even when not intended, if A was perceived by $S$ as causing a harm. ${ }^{19}$

According to Bratman, Davidson's model of belief/desire falls within the Simple View even though it reduces intentionality to the pair mentioned above. The problem of the relation between intention and intentional action is expressed in terms of a set of desires and beliefs that is responsible for the intentionality of action. ${ }^{20}$ Elizabeth Anscombe's conception, while approaching intention in its predictive and anti-mental dimension, assumes implicitly that action is intentional if it is possible to identify its reason in the agent's intention. Situations predicted by, for example, the Knobe's effect remain unexplained in Anscombe's and Davidson's conceptions. I do not want to say that the Simple View is wrong, but only that it does not make it possible to analyse many intentional actions that are not motivated by intention. I will consider two examples:

(1) Alice intends to mow the lawn. To perform this activity, she must complete several minor ones. She must start the mower, move it to and from, and so on. There is no reason to say that she performs each of these steps with a specific intention. Undoubtedly, however, each is intentional. Leaving aside situations in which there is an obstacle or a hindrance that requires a change of pace or lawn mowing technique, the entire process of mowing the lawn is intentional, albeit we may be justified in saying that its individual stages are not based on a series of specific intentions. ${ }^{21}$ According

19 F. Adams, A. Steadman, Intentional Action in Ordinary Language. Core Concept or Pragmatic Understanding? Analysis 64(2004), 173. See: M. Bratman, Intention, Plans and Practical Reason, Harvard University Press, Cambridge MA 1987; G. Harman, Practical Reasoning, Review of Metaphysics 29(1976)3, 431-463; A. Mele, Springs of Action, Oxford University Press, New York 1992.

20 M. Bratman, Two Faces of Intention, The Philosophical Review 93(1984)3, 375-376.

21 A. Mele, Decisions, intentions, and free will, Midwest Studies in Philosophy 24(2005), 150. 
to Bratman, this is a case of an intentional action that are is driven by specific intentions.

(2) A sniper intends to kill an officer. At the same time, he knows that when he takes the shot he will betray his location. It seems reasonable to say that the sniper does not intend to alarm the enemy, but does it regardless. The sniper does not have the intention of informing the enemy about his location; however, by shooting the enemy officer he does it intentionally. Let us now imagine that the sniper is aiming at the officer (with the intention of killing him), but does not want to raise the alarm. He does raise it, however, by accidentally pulling the trigger and killing the officer. ${ }^{22}$ How should we assess his action now? If he took the shot accidentally, then, even though he intended to shoot, there is a tendency to say that the pulling of the trigger was not an intentional action, just like the shivering of the hands is not intentional in a stressful situation. Taking the Simple View as our point of departure, it is difficult to answer the following question: if the sniper did not want to shoot at that specific moment, does it mean he did not kill the officer intentionally? All things considered, it does seem that the killing was intentional.

The examples above prove that the Simple View has a limited scope. There are a number of actions whose intentionality cannot be explained by referring to the agent's intentions.

Let's now go back to the problem raised by Knobe. The perspective he adopts concerns not so much the question about actions themselves as their relation with the so-called side-effects. Knobe claims that the result of an action is a side-effect if (1) the agent was not particularly trying to achieve it, but (2) he performed an action which he predicted will bring a given result. ${ }^{23}$ Hence, the side-effect of an action is unintended and is not an object of wanting, even if it is predicted to a certain extent.

22 G. Harman, Practical Reasoning, op. cit., 433.

23 J. Knobe,The Concept of Intentional Action, op. cit., 132. 
Based on the analysis of the two cases above and the concept of a side-effect, it is reasonable to say that what is crucial for the intentionality of some actions ${ }^{24}$ is their relation to predictions. $S$ performs an action $\varphi$ intentionally when $S$ predicts the consequences of $\varphi$ :

If $S$ is $\varphi$-ing intentionally, then $S$ predicts the consequences of $\varphi$-ing.

Alice's mowing of the lawn is an intentional act because she predicted the consequences her action will bring. The sniper killed the officer intentionally because he predicted that his shot will cause the officer's death. Even though the shot was accidental, the action was intentional. Similarly, the absence of his intention to alarm the enemy does not make his action unintentional because he knew the consequences that the action of shooting the rifle will bring.

\section{REASONS FOR ACTION AND FOLK PSYCHOLOGY}

My view is very close, but not identical, to that suggested by Adams, Mele and Bratman. The models of intentional action discussed in analytical philosophy of action attach considerable importance to the explanatory role of folk psychology (FP). In simple terms, folk psychology may be described as:

(FP1) a common-sense way of understanding different mental phenomena and a way of attributing beliefs, desires, intentions or emotions to others, ${ }^{25}$

and

24 That is intentional actions that cannot be explained by the Simple View.

25 Knobe, for example, does not want to reduce folk psychology only to a method for predicting and explaining human behaviour. He also treats it as a functional tool that facilitates the making of moral judgements. J. Knobe, Folk Psychology and Folk Morality: Response to Critics, Journal of Theoretical and Philosophical Psychology 24(2004)2, 270; 
(FP2) a basic way of explaining and predicting human actions. ${ }^{26}$

My account differs from the non-standard conception as it rejects FP2, while retaining FP1. I believe that any attempt to explain the intentionality of actions by identifying their reasons - understood as mental or psychological entities such as beliefs or desires - is doomed to fail. One example of this approach is Davidson's view that the (physical) cause of action is some non-physical state embodying the wanting/belief pair. Elizabeth Anscombe was aware of this aporia when she tried to analyse intentions in non-mental terms. ${ }^{27}$

To conclude this part of my analysis - there are many actions whose reasons are predictions of their potential consequences. To explain such actions, we must identify which of their reasons have the character of predictions. As for the belief in the explanatory value of folk-psychological concepts popular in analytical philosophy of action, I concluded that it restricts the analysis of action only

Experimental Philosophy, eds. J. Knobe, S. Nichols, Oxford University Press, New York 2008, 127. Although this is a very fertile account, we are not going to discuss it here.

26 I. Ravenscroft, Folk Psychology as a Theory, in: The Stanford Encyclopedia of Philosophy, ed. E. N. Zalta, (Fall 2016 Edition), URL = <https://plato.stanford.edu/archives/fall2016/ entries/folkpsych-theory/>. (accessed on 12.04.2017).

27 Rejection of FP2 is not tantamount to accepting eliminativism (let us recall: eliminativism claims that if (1) FP assumes the existence of beliefs and desires; (2) FP is false because it does not comply with the formal and pragmatic requirements of a scientific theory; and (3) the objects postulated by false scientific theories do not exist; then (4) beliefs and desires do not exist. P.M. Churchland, Eliminative Materialism and the Propositional Attitudes, Journal of Philosophy 78(1981), 570; S. Stich, From Folk Psychology to Cognitive Science, MIT Press, Cambridge MA 1983. Rather, I want to demonstrate that explaining intentional actions requires a broader research perspective than the one offered by analytical conceptions. In a way, this belief is expressed by Knobe in his later article Experimental Philosophy is Cognitive Science. There, he claims that the aim of experimental philosophy is the ultimate discovery of the cognitive mechanisms that will make it possible to explain specific mental processes having a critical relation to reasons and the intentionality of actions. 
to the relation between mental states and actions, whilst ignoring the entire cognitive and environmental context.

Based on the reflections above, I can now advance my first argument in support of the thesis of the predictive nature of reasons for action. The argument is as follows (weak version):

A1W - there can be actions that cannot be explained by reference to the category of intention, desire or belief.

The strong version of the argument goes as follows:

A1S - there are actions that cannot be explained with the categories of FP, that is with the language of propositional attitudes.

The argument may also be formulated in its radical version:

A1R - no actions can be explained with the categories of FP.

It is not possible at this stage to determine unequivocally which of the versions of $\mathbf{A} \mathbf{1}$ is true. I will answer this question later in the article.

\section{ACTION-ORIENTED PREDICTIVE PROCESSING}

According to the proponents of the theory of predictive processing ${ }^{28}$ the predictive attitude to perception is supposed to give access to all levels of sensory cognition. These levels are understood here as having a hierarchical order. The predictive attitude is sensitive to perceptive diversity, rather than just to the subtleties of conceptual categorisation as in the case of many other theories. In this conception, cognition is founded on hypotheses (predictions) about the causal structure of the world. These hypotheses impose a top-down structure on the bottom-up flow of sensory signals. They are determined, on the one hand, by the internal world model of a given cognitive

28 See: A. Clark, Whatever next? Predictive brains, situated agents, and the future of cognitive science, Behavioral and Brain Sciences 36(2013), 181-204. DOI: 10.1017/S0140525X12000477; A. Clark, Surfing Uncertainty. Prediction, Action and the Embodied Mind, Oxford University Press, Oxford 2016; J. Hohwy, The Predictive Mind, Oxford University Press, Oxford 2013. 
system, and, on the other, by changeable information coming from the world. These two layers are mutually restrictive, being dynamically interdependent. ${ }^{29}$ Drawing on knowledge of the causal relationships in the world, the mind advances hypotheses about the probability of certain events that minimise the so-called prediction error. ${ }^{30}$ These findings are based on the observation that sensory information does not influence perception directly. Rather, sensory stimuli are actively selected and appropriately used. Our expectations are driven by what is perceived and how individual aspects of our perception of the world are integrated. Hence, the problem of perception concerns the use of data that reach the brain through sensory inputs in such a way as to prevent the organism from making prediction errors. The errors, in turn, are caused by ignorance of the sources causing our sensory excitations. In practice, such ignorance may pose a threat to the organism.

We can never fully know how to act and which pieces of information reaching us through sensory channels will prove true. This is why I need to agree with Andy Clark's statement that perception is an actionoriented predictive process. ${ }^{31}$ This is an important observation, which allows us to treat perception as the very element in our psychophysical structure able to explain the dynamics and involvement of the organism in a specific environment - not only its method of cognition, but also its method of acting which is strictly correlated with actions. ${ }^{32}$ The purpose of predictions is to organise specific

29 J. Hohwy, The Predictive Mind, op. cit., 69-70.

30 The mind does this in two ways: (1) by reviewing the generative model and the hypothesis adopted (passive inference); or (2) by acting in the world in a manner that helps maintain the hypothesis advanced by the model (active inference). K. J. Friston, The free-energy principle: A unified brain theory?, Nature Neuroscience 11(2010), 129.

31 A. Clark, Whatever next?, op. cit., 184.

32 This statement is supported by neurological arguments provided by the analysis of visual processes carried out by Milner and Goodale. The authors evocatively demonstrate that perceptive coding is subordinate to and directly dependent on coding related to action control. A.D. Milner, M.A. Goodale, The Visual Brain in Action, Oxford University Press, Oxford 2004. 
cognitive and non-cognitive aims pursued by organisms. Therefore, they serve a specific normative function in all interactions between a cognitive system and its environment. ${ }^{33}$ Among other reasons, the function is normative because perceptive situations are always marked by normative uncertainty. Normative uncertainty is closely related to our ignorance of how we should act in an environment that is always indeterminate. The implications of this uncertainty are not only moral, but also, and primarily, non-moral to the extent that they relate to the problem of making decisions and taking appropriate action in the world given through perception. ${ }^{34} \mathrm{I}$ will examine this issue further in what follows.

\section{DECISION-MAKING FROM THE PERSPECTIVE OF PREDICTIVE PROCESSING}

The hypothesis of predictive processing can be employed not only to explain brain activity, ${ }^{35}$ but also as a basis for understanding such phenomena as action, cognition, learning, and many others. ${ }^{36}$ According to Christopher Burr, the predictive hypothesis can also be used in relation to embodied decision-making processes. ${ }^{37}$

33 See: M. Piekarski, Normativity of Perception and the Predictive Processing, in: Die Philosophie der Wahrnehmung und Beobachtung / The Philosophy of Perception and Observation, eds. Ch. Limbeck-Lilienau, F. Stadler, Austrian Ludwig Wittgenstein Society, Kirchberg am Wechsel 2017, 199-201; M. Piekarski, Commentary: Brain, Mind, World: Predictive Coding, Neo- Kantianism, and Transcendental Idealism, Frontiers in Psychology (2017), 8:2077, DOI: 10.3389/fpsyg.2017.02077.

34 For more details about reasoning in situations of normative uncertainty, see T. Żuradzki, Meta-Reasoning in Making Moral Decisions under Normative Uncertainty, in: Argumentation and Reasoned Action: Proceedings of the $1^{\text {st }}$ European Conference on Argumentation. Vol. II, ed. D. Mohammed, M. Lewiński, College Publications, London 2015, 1093-1104.

35 J. Hohwy, The Predictive Mind, op. cit., 2.

36 A. Clark, Surfing Uncertainty. Prediction, Action and the Embodied Mind, op. cit.

37 Ch. Burr, Embodied Decisions and the Predictive Brain, in: Philosophy and Predictive Processing, eds. T. Metzinger, W. Wiese, MIND Group, Frankfurt am Main 2017. DOI: 10.15502/9783958573086. 
Predictionism in decision theory helps avoid many mistakes made in classical approaches, including the belief that a decision-making process may be easily reduced to two factors, i.e. deliberative processes (assessing the value of specific variables) and selection of appropriate actions. In this account, decision-making is one of the many actions typically performed by the cognitive system according to a traditional understanding of perception as a static and passive process moving from sensory information to representations based on such information. ${ }^{38}$ Paul Cisek suggests explaining decision-making processes on the basis of the ACH (Affordance Competition Hypothesis) model. According to this model, decisions emerge from distributed and probabilistic competence occurring between overlapping representations of possible actions and sensory-motor information. These decisions are not determined by one specific instance in the brain, but by a region carrying out a given action in such a way as to influence other regions. This leads to the so-called distributed consensus. Hence, decisions are based on a mutual influence between specific actions performed by relevant areas in the brain (from rules of action formulated at the level of the prefrontal cortex ${ }^{39}$ to the activity of peripheral basal ganglia making predictions for other peripheral regions - to the operation of relevant subcortical areas responsible for the correct functioning of sensory modalities and motor skills). Cisek and Pastor-Bernier have stressed that neural representations work as indicators of potential actions adapted to the environment of the agent. ${ }^{40}$

38 Ibidem, 3-4; P. Cisek, Making decisions through a distributed consensus, Current Opinion in Neurobiology 22(2012)6, 927-936.

39 It has been demonstrated that people with damage to this part of the brain have great difficulty in matching their actions to changing environmental conditions. See M. Koenigs, L. Young, R. Adolphs, D. Tranel et al, Damage to the prefrontal cortex increases utilitarian moral judgements, Nature 446(2007), 908-911, DOI: 10.1038/nature05631.

40 P. Cisek, A. Pastor-Bernier, On the challenges and mechanisms of embodied decisions, Philosophical Transactions of the Royal Society B: Biological Sciences 369(2014), 4. 
According to Burr ${ }^{41}$ the $\mathrm{ACH}$ model dovetails with and is complemented by the predictive processing framework, according to which neuronal representations of actions may qualify as predictions depending on the unstable and uncertain environment. Representations in the $\mathrm{ACH}$ model, however, have satisfaction conditions, that is they are directly involved in the process of minimizing the prediction error (active reasoning). ${ }^{42}$ In line with the predictive hypothesis we should conclude that neural representations of actions do have the character of predictions, although this may change in response to a dynamic and uncertain environment. ${ }^{43}$ Importantly, the representations postulated by the $\mathrm{ACH}$ model can be employed specifically to explain perceptual processes. They are rooted in specific facts relating to the embodiment of a given cognitive system. Thus, their function is modal. ${ }^{44}$ We should therefore conclude that the decision-making process must be understood dynamically: the action selection process in the $\mathrm{ACH}$ unfolds fluidly at different levels of the hierarchy tracking environmental and bodily regularities at different time scales. Thus, a specific decision is made on the basis of: (1) information coming from the sensory signal, (2) representations of actions that qualify as predictions, and (3) an uncertain and changeable environment. Thus, rather than being a simple process of deliberation and making commitments, the decision-making process is part of an embodied cognitive process situated in the environment ${ }^{45}$.

41 See Ch. Burr, Embodied Decision and the Predictive Brain, op. cit. for a detailed analysis of this problem.

42 See: V. Gallese, T. Metzinger, Motor ontology: The representational reality of goals, actions and selves, Philosophical Psychology 16(2003)3, 365-388.

43 Ch. Burr, Embodied Decision and the Predictive Brain, op. cit., 6.

$44 \mathrm{Ch}$. Burr, M. Jones, The body as laboratory: Prediction- error minimization, embodiment, and representation, Philosophical Psychology 29(2016)4, 586-600.

45 See also: M. Piekarski, Commentary: Getting into predictive processing's great guessing game: Bootstrap heaven or hell?, Frontiers in Psychology (2017), 8:1244, DOI: 10.3389/ fpsyg.2017.01244; G. Pezzulo, P. Cisek, Navigating the affordance landscape: Feedback 


\section{THE CASE FROM PREDICTIVE PROCESSING: A SECOND ARGUMENT}

The above analysis leads to the following conclusions:

(T1) the explanation of a given event is strictly related to identifying a specific cognitive mechanism at its origin;

(T2) the relevant mechanism may be described by the theory of predictive processing in terms of the generative model and predictive inference;

(T3) by identifying a specific prediction (or set of predictions), we identify a reason according to which the agent decided to perform a given action.

Theses T1-T3 allow us to advance argument A2 in support of the hypothesis of the predictive nature of reasons for action. The argument is as follows:

A2 - to explain a given action is to identify a relevant predictive inference that led to the action.

By accepting argument A2, we thereby accept A1S and reject A1W. It is difficult to ascertain whether A1R is fully justified. Our analysis is not decisive in this respect. According to the predictive hypothesis, each action is preceded by a process of predictive processing. In other words, the type of coding focused on action control and performance is subordinated to predictive processing. We should conclude, therefore, that all unintentional actions, i.e. behaviours, are possible only when the generative model (whereby we can describe our mind) advances relevant perceptive hypotheses and performs relevant active inferences. By adopting such and such predictions, the cognitive system has access to such and such pool of potential actions.

control as a process model of behavior and cognition, Trends in Cognitive Sciences 6(2016), 414-424. 


\section{CONCLUSION}

In this article we have presented two strong arguments (A1S and A2) supporting the thesis of the predictive nature of reasons for action. Accepting these arguments is of paramount importance for the problem of the application of FP categories to explain human behaviour. It might seem that both arguments lead to a radical conclusion that denies any explanatory value to $\mathrm{FP}$ concepts such as desires, beliefs, intentions or attitudes. Does this mean that such concepts are devoid of meaning, or that they are nothing more than linguistic artefacts? Not necessarily. The implication is rather that their applicability to the problem of explaining the categories of action is much restricted. As we have demonstrated, (1) there are actions that cannot be described satisfactorily with the categories of FP; and - more importantly - (2) the category of action does not belong to FP. Actions should be considered in the context of their relation to the entirety of the agent's cognitive processes, preferences and emotions, as well as his environment and the cultural and social dimension of agency. If so, what about FP?

It does not seem that explaining human behaviour through intentional concepts and competences is unjustified. People will keep explaining their own actions and the actions of others with the language of propositional attitudes. We should be aware, however, that explanations based on the categories of folk psychology are personal. This means that they are horizontal, i.e. intra-level as José Luis Bermúdez puts it. ${ }^{46}$ The explanans is at the same level as the explanandum: the former precedes the latter in time and, in a way, causes it. ${ }^{47}$ Personal explanations should be contrasted with

46 J.L. Bermúdez, Philosophy of Psychology: A Contemporary Introduction, Routledge, London 2005, 31-35.

47 P. Gładziejewski, Wyjaśnianie za pomoca reprezentacji mentalnych. Perspektywa mechanistyczna, FNP, Warszawa - Toruń 2015, 337-338. From the perspective of cognitive 
sub-personal explanations, that is vertical explanations. The latter are inter-level - higher-level phenomena are explained by reference to lower-level phenomena. Our analysis has shown that, if an action is not isolated from other activities of the embodied agent such as cognition, decision-making, risk avoidance, etc., it should be explained through vertical explanations. In light of the predictive hypothesis, this is strictly related to the process of referring to subsequent levels of the generative model. Predictions made by the cognitive system at lower levels of the model (for example connected to the performance of specific intentional actions) are justified by predictions at higher levels of this hierarchical structure.

In conclusion: to identify a reason for an action is to identify predictions made by the cognitive system. Such predictions, however, cannot be reduced to intentions, but to the need to reduce tension and normative uncertainty. ${ }^{48}$ Therefore, the reason for a given action is the need to minimise the prediction error, which may also be described as the need to minimise normative uncertainty.

science, however, they are not strictly speaking explanations, but rather a commonsense way of understanding mental phenomena.

48 According to proponents of predictive processing this need drives brain activity, from the most basic cellular processes to complex mental operations. See: A. Clark, A nice surprise? Predictive processing and the active pursuit of novelty, Phenomenology and the Cognitive Sciences (2017), 1-14. DOI: 10.1007/s11097-017-9525-z; A. Clark, Beyond the 'Bayesian Blur': Predictive Processing and the Nature of Subjective Experience, Journal of Consciousness Studies (2017), 1-31; K.J. Friston, The free-energy principle: a rough guide to the brain?, Trends in Cognitive Science 13(2009)7, 293-301. DOI: 10.1016/j. tics.2009.04.005; K.J. Friston, J. Daunizeau et al., Action and behavior: a free-energy formulation, Biological Cybernetics 102(2010)3, 227-260; P. Schwartenbeck et al., Exploration, novelty, surprise, and free energy minimization, Frontiers in Psychology (2013), 4:710, DOI: 10.3389/fpsyg.2013.00710. 


\section{REFERENCES}

Adams F., Intention and Intentional Action. The Simple View, Mind and Language 4(1986)1, 281-301.

Adams F., Steadman A., Intentional Action in Ordinary Language. Core Concept or Pragmatic Understanding?, Analysis 64(2004), 173-181.

Anscombe G. E. M., Intention, Harvard University Press, Cambridge MA 1957.

Bermúdez J.L., Philosophy of Psychology: A Contemporary Introduction, Routledge, London 2005.

Bratman M., Two Faces of Intention, The Philosophical Review 93(1984)3, 375-376.

Bratman M., Intention, Plans and Practical Reason, Harvard University Press, Cambridge MA 1987.

Burr Ch., Embodied Decisions and the Predictive Brain, in: Philosophy and Predictive Processing, eds. T. Metzinger, W. Wiese, MIND Group, Frankfurt am Main 2017. DOI: $10.15502 / 9783958573086$.

Burr Ch., Jones M., The body as laboratory: Prediction-error minimization, embodiment, and representation, Philosophical Psychology 29(2016)4, 586-600.

Cisek P., Making decisions through a distributed consensus, Current Opinion in Neurobiology 22(2012)6, 927-936.

Cisek P., Pastor-Bernier A., On the challenges and mechanisms of embodied decisions, Philosophical Transactions of the Royal Society B: Biological Sciences 369(2014), 1655.

Clark A., Whatever next? Predictive brains, situated agents, and the future of cognitive science. Behavioral and Brain Sciences 36(2013), 181-204. DOI: 10.1017/ S0140525X12000477.

Clark A., Surfing Uncertainty. Prediction, Action and the Embodied Mind, Oxford University Press, Oxford 2016.

Clark A., A nice surprise? Predictive processing and the active pursuit of novelty, Phenomenology and the Cognitive Sciences (2017), 1-14. DOI: 10.1007/ s11097-017-9525-z.

Clark A., Beyond the 'Bayesian Blur': Predictive Processing and the Nature of Subjective Experience, Journal of Consciousness Studies (2017), 1-31.

Churchland P.M., Eliminative Materialism and the Propositional Attitudes, Journal of Philosophy 78(1981)2, 67-90.

Cushman F., Mele A., Intentional Action: Two-and-Half Folk Concepts? in: Experimental Philosophy, eds. J. Knobe, S. Nichols, Oxford University Press, New York 2008, 171-188. 
Davidson D., Actions, Reasons and Causes, The Journal of Philosophy 60(1963)23, 685-700.

Davidson D., Freedom to Act, in: D. Davidson, Essays on Actions and Events, Clarendon Press, Oxford 2001, 63-82.

Friston K.J., The free-energy principle: a rough guide to the brain?, Trends in Cognitive Science 13(2009)7, 293-301. DOI: 10.1016/j.tics.2009.04.005.

Friston K.J., The free-energy principle: A unified brain theory?, Nature Neuroscience 11(2010), 127-138.

Friston K.J., Daunizeau J. et al., Action and behavior: a free-energy formulation, Biological Cybernetics 102(2010)3, 227-260.

Gallese V., Metzinger T., Motor ontology: The representational reality of goals, actions and selves, Philosophical Psychology 16(2003)3, 365-388.

Gładziejewski P., Wyjaśnianie za pomoca reprezentacji mentalnych. Perspektywa mechanistyczna, FNP, Warszawa - Toruń 2015.

Harman G., Practical Reasoning, Review of Metaphysics 29(1976)3, 431-463.

Hohwy J., The Predictive Mind, Oxford University Press, Oxford 2013.

Knobe J., Intentional Action and Side Effects in Ordinary Language, Analysis 63(2003)3, 190-193.

Knobe J., Folk Psychology and Folk Morality: Response to Critics, Journal of Theoretical and Philosophical Psychology 24(2004)2, 270-279.

Knobe J., The Concept of Intentional Action: A Case Study in the Uses of Folk Psychology, in: Experimental Philosophy, eds. J. Knobe, S. Nichols, Oxford University Press, New York 2008, 129-148.

Knobe J., Experimental Philosophy is Cognitive Science, in: A Companion to Experimental Philosophy, eds. J. Sytsma, W. Buckwalter, Willey-Blackwell, West Sussex 2016.

Experimental Philosophy, eds. J. Knobe, N. Nichols, Oxford University Press, New York 2008.

Koenigs M., Young L., Adolphs R., Tranel D., et al, Damage to the prefrontal cortex increases utilitarian moral judgements, Nature 446(2007), 908-911, DOI: 10.1038/ nature 05631.

Machery E., Mallon R., Nichols S., Stich S., Semantics, cross-cultural style, Cognition 3(2004), 1-12.

McCann H., Rationality and the Range of Intention, Midwest Studies in Philosophy 10(1986)1, 191-211.

McDowell J., Anscombe on Bodily Self-Knowledge, in: Essays on Anscombe's Intention, ed. A. Ford, J. Hornsby, F. Stoutland, Harvard University Press, Cambridge MA 2011, 128-146. 
Mele A., Springs of Action, Oxford University Press, New York 1992.

Mele A., Intentional action: Controversies, data, and core hypotheses, Philosophical Psychology 2(2003), 325-340.

Mele A., Decisions, intentions, and free will, Midwest Studies in Philosophy 24(2005),146-152.

Milner A.D., Goodale M. A., The Visual Brain in Action, Oxford University Press, Oxford 2004.

Nadelhoffer T., Blame, Badness, and Intentional Action: A Reply to Knobe and Mendlow, Journal of Theoretical and Philosophical Psychology 24(2004), 259-269.

Nichols S., Ulatowski J., Intuitions and Individual Differences: The Knobe Effect Revisited, Mind and Language 4(2007), 346-365.

Paprzycka K., Rozwiqzanie problemu Butlera i wyjaśnienie efektu Knobe’a, Filozofia Nauki 22(2014)2, 73-96.

Pezzulo G., Cisek P., Navigating the affordance landscape: Feedback control as a process model of behavior and cognition, Trends in Cognitive Sciences 6(2016), 414-424.

Piekarski M., Efekt Knobe'a, normatywność $i$ racje dziatania, Filozofia Nauki 97(2017)1, 109-128.

Piekarski M., Normativity of Perception and the Predictive Processing, in: Die Philosophie der Wahrnehmung und Beobachtung / The Philosophy of Perception and Observation, eds. Ch. Limbeck-Lilienau, F. Stadler, Austrian Ludwig Wittgenstein Society, Kirchberg am Wechsel 2017, 199-201.

Piekarski M., Commentary: Getting into predictive processing's great guessing game: Bootstrap heaven or hell?, Frontiers in Psychology (2017), 8:1244. DOI: 10.3389/ fpsyg.2017.01244.

Piekarski M., Commentary: Brain, Mind, World: Predictive Coding, Neo- Kantianism, and Transcendental Idealism, Frontiers in Psychology (2017), 8:2077. DOI: 10.3389/fpsyg.2017.02077.

Ravenscroft I., Folk Psychology as a Theory, in: The Stanford Encyclopedia of Philosophy, ed. E.N. Zalta, (Fall 2016 Edition), URL = <https://plato.stanford.edu/ archives/fall2016/entries/folkpsych-theory/>. (accessed on 12.04.2017).

Schwartenbeck P., et al., Exploration, novelty, surprise, and free energy minimization, Frontiers in Psychology 2013, 4:710. DOI: 10.3389/fpsyg.2013.00710.

Stich S., From Folk Psychology to Cognitive Science, MIT Press, Cambridge MA 1983.

Stoecker R., Davidson, in: A Companion to the Philosophy of Action, eds. T. O'Connor, C. Sandis, Blackwell, Oxford 2010, 598-605.

Żuradzki T., Meta-Reasoning in Making Moral Decisions under Normative Uncertainty, in: Argumentation and Reasoned Action: Proceedings of the $1^{\text {st }}$ European 
Conference on Argumentation. Vol. II, eds. D. Mohammed, M. Lewiński, College Publications, London 2015, 1093-1104.

The research for this paper was financially supported by the Polish National Science Centre, under decision DEC-2017/01/X/HS1/00165.

Michat PIeKarski

m.piekarski@uksw.edu.pl

Cardinal Stefan Wyszynski University in Warsaw, Institute of Philosophy

Wóycickiego 1/3, 01-938 Warsaw, Poland

DOI:10.21697/spch.2018.54.1.14 